\title{
Effect of restorative techniques on fracture resistance of endodontically treated premolars
}

\author{
Bandar M. A. Al-Makramani ${ }^{*}$, Abdul A. A. Razak $^{2}$, Ng M. Yi ${ }^{3}$, Sin Y. Ying ${ }^{3}$, Fuad A. Al-Sanabani ${ }^{4}$ \\ ${ }^{1}$ Department of Conservative Dentistry, Faculty of Dentistry, Sana'a University, Sana'a, Yemen \\ ${ }^{2}$ Department of Conservative Dentistry, Faculty of Dentistry, University of Malaya, Kuala Lumpur, Malaysia \\ ${ }^{3}$ Dental Student, Faculty of Dentistry, University of Malaya, Kuala Lumpur, Malaysia \\ ${ }^{4}$ Department of Prosthodontics, Faculty of Dentistry, Sana'a University, Sana'a, Yemen \\ Email: ${ }^{*}$ makramani@yahoo.com
}

Received 20 September 2013; revised 15 October 2013; accepted 17 October 2013

Copyright (C) 2013 Bandar M. A. AL-Makramani et al. This is an open access article distributed under the Creative Commons Attribution License, which permits unrestricted use, distribution, and reproduction in any medium, provided the original work is properly cited.

\begin{abstract}
Purpose: This study was aimed to evaluate the effect of restorative materials and glass fiber post on the fracture resistance of endodontically treated premolars. Material and Methods: Fifty extracted single rooted lower premolars were used in this in vitro study and divided into 5 groups: sound teeth (control group); mesial-occlusal-distal (MOD) preparation + endodontic treatment + composite restoration; MOD preparation + endodontic treatment + glass fiber post + composite restoration; MOD preparation + endodontic treatment + amalgam restoration; MOD preparation + endodontic treatment + glass fiber post + amalgam restoration. The specimens were loaded on a universal testing machine at the crosshead speed of $1 \mathrm{~mm} / \mathrm{min}$ until fracture. The data were analyzed using two-way ANOVA test. Results: The mean loads at fracture were $860.11 \mathrm{~N}, 801.79 \mathrm{~N}, 761.39 \mathrm{~N}, 737.14$ $\mathrm{N}$ and $707.85 \mathrm{~N}$ respectively. There were no statistically significant differences $(P>0.05)$ in the fracture resistance of teeth restored with composite and amalgam, as well as restored with or without glass fiber post. Conclusions: The type of restorative material and the usage of glass fiber post do not have visible influence on the fracture resistance of the endodontically treated mandibular premolars.
\end{abstract}

Keywords: Endodontic Treatment; Fiber Post; Fracture Resistance

\section{INTRODUCTION}

Endodontically treated (endo-treated) teeth are often compromised by structural destruction from dental caries,

"Corresponding author. fractures, previous restorations and endodontic treatment [1-4]. The restoration of endo-treated teeth has always been a challenge to the clinician. Although the fracture potential of endo-treated teeth has been studied, yet to date, no definite relationship has been established between fracture and the type of restoration [5].

Root canal treatment should not be considered complete until the permanent restoration has been placed [6]. There are a few requirements for an adequate restoration of an endo-treated tooth. The restoration must provide a coronal seal, protect the remaining tooth structure, minimize the cuspal flexure and satisfy function and aesthetics [7].

Besides a crown, there are other restorative materials which are used to restore endo-treated tooth. These include silver amalgam alloy, composite resin, glass ionomer cement and resin modified glass ionomer materials [8]. Dental amalgam and composite resins are the most commonly used ones [9].

Dental amalgam has been characterized as technically easy to use and a clinically predictable material, with favorable mechanical properties [10]. The use and success rate of dental amalgams have been well documented and they are the most cost effective materials in posterior teeth restorations, but they are declining in use in dentistry mainly due to the unaesthetic appearance and concerns about the hazard of mercury [11-13]. The evidence suggests that complex amalgam restorations exhibit surprising durability and may have sufficient strength to protect the remaining tooth structure [14].

As alternatives to amalgam, direct adhesive restorative techniques with composite resin have been proposed, since these materials bond to tooth structure, and thus increase fracture resistance [15-17]. However, composite resin cores are not as dimensionally stable as amalgam 
[18]. It also demonstrates high polymerization shrinkage which will cause stress on the adhesive bond [19]. The stress will lead to debonding at the weakest interface and hence cause fracture in a composite restored tooth [20]. The difficult handling properties, such as creation of a tight gingival seal and restoration of anatomic form and contact point, are additional limitations of composite resin materials [21].

The final restoration of an endo-treated premolar may require a post as it is bulkier than anterior teeth and often are single-rooted with relatively small pulp chambers [22]. Traditionally, custom made casted posts and cores covered by metal or porcelain-fused-to-metal crowns were the restorations of choice [23]. In the 1970s prefabricated metal posts were made available [24].

Today, prefabricated ceramic and fiber-reinforced posts are getting more and more popular [23]. The recently developed fiber post has similar biomechanical properties to dentine [25]. The main purpose of the post is to retain the core in case of extensive loss of coronal tooth structure [22]. However, inserting a fiber post into a root canal for restoration retention has not always improved fracture resistance. But it was noted that they improved fracture patterns from non-restorable to restorable [5]. It has been claimed that the placement of a fiber post may play a protective role for teeth with a substantial degree of coronal destruction [26]. A recent prospective clinical trial has revealed that premolars with posts have a significantly higher success rate than those restored without post over a two-year observation period [26].

However, because of the tendency of the post to weaken the roots and cause root fracture, post should only be used to retain core within restoration of the endo-treated teeth when no other alternative options are available [2]. Preparation of a post space may increase risk to a restorative procedure. These accidents include perforation in the apical portion of the root or into the lateral fluted areas of the midroot, a so-called "strip perforation" [22]. Therefore, this study was conducted to assess the effect of restorative materials on the fracture resistance of endotreated premolar teeth. In addition, this study evaluated the effect of glass fiber post on the fracture resistance of endo-treated premolar teeth. The hypotheses to be tested were: 1) there would be no difference in fracture strength between endo-treated teeth restored with amalgam core and composite core restorations, and 2) the use of glass fiber post in endo-treated teeth would not influence the fracture strength.

\section{MATERIAL AND METHODS}

Two restorative materials, nanocomposite (Filte Z350 Universal Restorative A3.5 Shade, 3M ESPE, USA) and amalgam (Dispersalloy amalgam capsule, Dentsply Caulk, USA) were used in this study. In addition, glass fiber post (Radix Fiber Post, Dentsply Maillefer, France) and a universal resin luting cement (RelyX U100, 3M ESPE, Seefeld, Germany) were used.

Intact extracted single rooted human mandibular premolars were collected and stored in solution of $0.9 \%$ normal saline to avoid desiccation. The collected teeth were free of cracks and fractures, had no evidence of caries or restorations and had no previous endodontic treatment. The premolars were cleaned off calculus and periodontal tissue using an ultrasonic scaler (EMS, Adec, USA). After that, all teeth were disinfected in $0.5 \%$ chloramine $\mathrm{T}$ trihydrate solution for 1 week. The teeth were then stored in distilled water at $4^{\circ} \mathrm{C}$ (ISO/TS $11405 / 2003$ ) until further processing. To minimize deterioration, the storage medium was changed every one week. From the total number of teeth collected, 50 mandibular premolars with almost similar size and shape were selected by measuring its buccal-lingual, mesialdistal crown width and tooth length in millimeters using a digital caliper (Electronic Digital Calliper, Mitutoyo Corp, Tokyo, Japan) (mean width: $7.54 \times 8.39 \mathrm{~mm}$, mean tooth length: $21.82 \mathrm{~mm}$ ). All teeth were radiographed in proximal direction to ensure that the selected teeth have only 1 canal, no internal resorption or canal abnormalities. The selected specimens were examined at $20 \times$ magnification, using a stereoscopic microscope (Olympus SZ2-1LST, Olympus Corp., Tokyo, Japan) to ensure fracture-free roots.

The 50 selected teeth were randomly assigned to 5 groups of 10 specimens each. Group 1 served as a control group (intact teeth). Group 2 and Group 3 were assigned for composite restoration, with prefabricated fiber post inserted into the samples of Group 3 prior to the composite restoration. Group 4 and Group 5 were assigned for amalgam restoration, with fiber post inserted into the samples of Group 5 prior to the amalgam restoration. The groups are illustrated in Table 1.

Prior to MOD cavity preparation, the specimens were mounted in impression compound blocks to ensure good grip and control movement during manipulation. A standardized MOD cavity preparation was prepared for all groups except for the control group. MOD measurement: buccal-lingual width and the depth of the occlusal isthmus were $2 \mathrm{~mm}$; buccal-lingual width of the proximal preparation was $3 \mathrm{~mm}$, width of the gingival floor was $1.0 \mathrm{~mm}$ and the height of the axial wall was $1.5 \mathrm{~mm}$. The preparation was done by one operator for standardization purposes.

Endodontic procedure was carried out on all groups except Group 1 (control group). An endodontic access cavity with straight line access, as determined by the outline of the pulp space, was prepared. The pulp chamber and pulp horn were unroofed. The pulp was first extirpated with a barbed broach (Dentsply Maillefer, 
Table 1. Grouping of sample.

\begin{tabular}{ccc}
\hline Group & Abbreviation & Description \\
\hline 1 & ST & Sound teeth (control group) \\
2 & MOD-C & Mesial-occlusal-distal preparation + endodontic treatment + composite resin \\
3 & MOD-P-C & Mesial-occlusal-distal preparation + endodontic treatment + glass fiber post + composite resin \\
4 & MOD-A & Mesial-occlusal-distal preparation + endodontic treatment + amalgam restoration \\
5 & MOD-P-A & Mesial-occlusal-distal preparation + endodontic treatment + glass fiber post + amalgam restoration \\
\hline
\end{tabular}

Ballaigues, Switzerland). The canal patency was established with a size $10 \mathrm{~K}$-file (Dentsply Maillefer, Ballaigues, Switzerland). The file was placed in the canal with light pressure until its tip was just visible at the apical foramen. The true working length was set at $1.0 \mathrm{~mm}$ short of this file length. After the working length was accomplished, the apical canal was prepared using $\mathrm{K}$-files. The teeth were only included if the first file that bind to the canal wall up to the working length was size $20 \mathrm{~K}$-file. The apical sections were further instrumented with 3 larger K-flies (size 25, 30, 35) using circumferential filing up to working length. Thereby, the master apical file used was size 35 at working length. The apical third of the canal was prepared using a step-back technique in $1 \mathrm{~mm}$ increments with each larger size. After each filing, the canals were repeatedly irrigated with 3.0 $\mathrm{mL}$ of $2.5 \%$ sodium hypochlorite solution $(\mathrm{NaOCl})$ (Clorox, Clorox Inc, Malaysia). After canal preparation, the teeth were obturated with gutta-purcha (Dentsply Maillefer, Ballaiguis, China) and endodontic sealer (Top Seal, Dentsply Maillefer, Ballaiguis, Switzerland) using the lateral condensation technique. All procedures were done by a single operator for standardization purposes.

After 24 hours, the gutta-purcha was removed for specimens in Group 3 and 5 only. Prior to preparation of the post space, the gutta-purcha was removed with peesoreamer burs size 1 (LRGO Peeso Reamer, REF A 0009-1, Dentsply Maillefer, Ballaigues, Switzerland). The burs were adjusted with a rubber stopper to $4 \mathrm{~mm}$ shorter than the working length of each tooth, leaving behind $4 \mathrm{~mm}$ of gutta-purcha at the apical portion of the root.

Post space preparation was done using a low speed drill size 2 (Easy Post Precision Drills, REF C060-2, Dentsply Maillefer, France) provided by the manufacturer of the fiber post system used (Radix Fiber Post, Dentsply Maillefer, France). The size of the drill was the same as the size of the fiber post to be used, which was standardized at the diameter of $0.8 \mathrm{~mm}$ at the apical portion and $1.47 \mathrm{~mm}$ at the coronal portion. The post length was standardized at $1 \mathrm{~mm}$ of post embedded into the restoration for all samples in Group 3 and 5. Once the post length was measured, the excess length at the coronal part of the fiber post was cut using a diamond bur (2979.314.014, Komet, Rock Hill, SC, USA).
All posts were cemented using self-adhesive universal resin cement (RelyX U100, 3M ESPE, Germany) according to manufacturer's instructions. All samples in Group 2 and 3 with MOD cavity preparation were restored with nanocomposite (Filtek Z350, 3M ESPE, USA). Whereas, the samples in Group 4 and 5 with MOD cavity preparation were restored with amalgam (Dispersalloy amalgam capsule, DENTSPLY Caulk, USA). All procedures were done by one operator to avoid variability.

The teeth were removed from the impression compound blocks. The root surface of all samples was marked with a marker pen throughout the perimeter at 2 $\mathrm{mm}$ below the cemento-enamel junction. The area apical to this line was painted with hydrophilic vinyl polysiloxane impression material (GC Exaflex regular, GC America, Alsip, USA) to simulate the periodontal ligament of a natural tooth. A dental surveyor was used to position the long axis of the teeth vertically. Each sample was then embedded along its long axis into cold-cure epoxy resin (Mirapox 950 - 230 A/B, Miracon Sdn Bhd, Malaysia) contained inside a cylindrical plastic mould (Figure 1). The samples were left for 24 hours to allow complete setting of the epoxy resin.

All samples were stored in water at $37^{\circ} \mathrm{C}$ for 24 hours prior to thermocycling. Thermocycling (Thermocycling machine, Faculty of Engineering, University of Malaya, Malaysia) was then carried out between $5^{\circ} \mathrm{C}$ and $5^{\circ} \mathrm{C}$ using 20 seconds dwell times with a 5 seconds transfer interval. This procedure was carried out according to ISO (ISO/TS 11405/2003).

The mounted specimens were placed on the lower compartment of a high precision universal testing machine (Shimadzu, Shimadzu Corp., Tokyo, Japan). A 2 $\mathrm{mm}$ stainless steel bar, mounted on the crosshead of the Shimadzu testing machine was used and applied a compressive load along the long axis of the tooth at a crosshead speed of $1 \mathrm{~mm} / \mathrm{min}$ until failure occurred (Figure 2). The $2 \mathrm{~mm}$ stainless steel bar was applied at the restoration and the occlusal inclines of the buccal and lingual cusps to standardize loading point to all specimens. The load at failure was recorded as the maximum force during loading. The data were statistically analyzed using a computer program (SPSS version 15.0, SPSS Inc., Chicago, IL, USA). A two-way ANOVA test was performed 


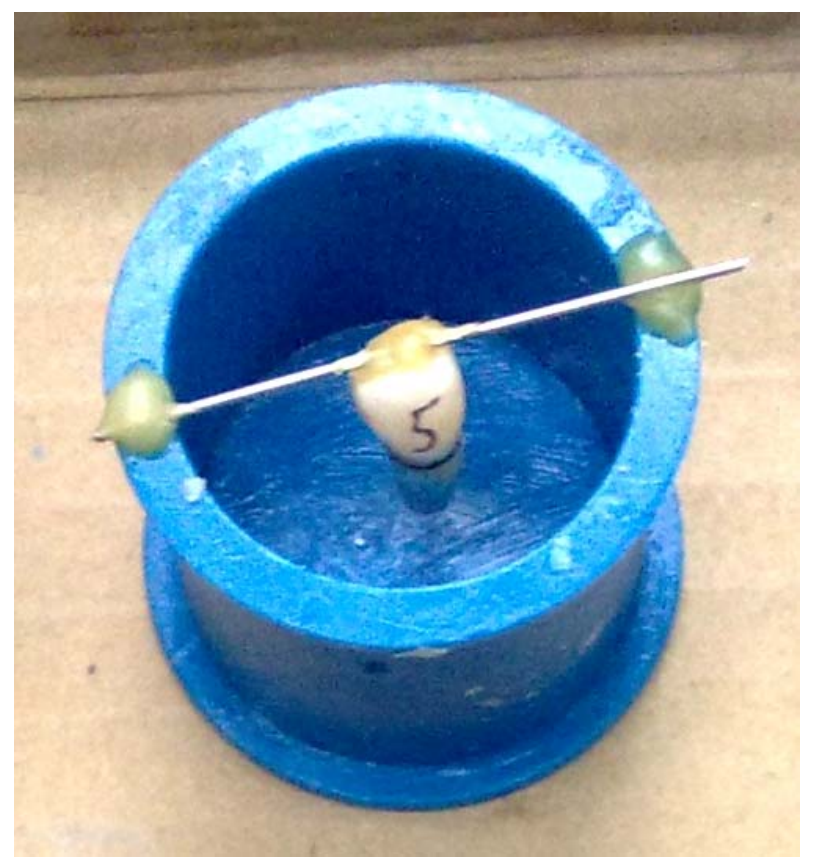

Figure 1. The tooth inside plastic mould ready to be embedded in resin.

for the comparison of the fracture load of the different groups. Statistical significance was set at $\alpha=0.05$.

\section{RESULTS}

The values of the mean force of fracture for the 5 groups are listed in Table 2. Groups MOD-C and MOD-P-C, which used the composite restoration, showed higher fracture resistance than groups MOD-A and MOD-P-A, in which the amalgam restoration was used. However, there were no significant differences among the 5 groups as indicated by the two-way ANOVA test $(P=0.949)$.

There was no statistically significant difference between the group restored with nanocomposite (MOD-C) and the group restored with amalgam (MOD-A) $(P=$ $0.551)$. In addition, the two groups with glass fiber posts (MOD-P-C and MOD-P-A) did not show any statistically significant difference with the groups without glass fiber posts (MOD-C and MOD-A) $(P=0.688)$.

\section{DISCUSSION}

In this in vitro study, extracted human lower premolars were used to assess the fracture resistance of endotreated teeth restored with glass fiber post and different restorative materials. Although the teeth were carefully selected for similar dimensions, it remains impossible to avoid variations in the mechanical and physical properties of natural teeth. These variations might have accounted for the large standard deviation observed in the results of this study. Similarly, this has been reported in other studies $[9,27,28]$. Therefore, The buccal-lingual, mesial-dis-

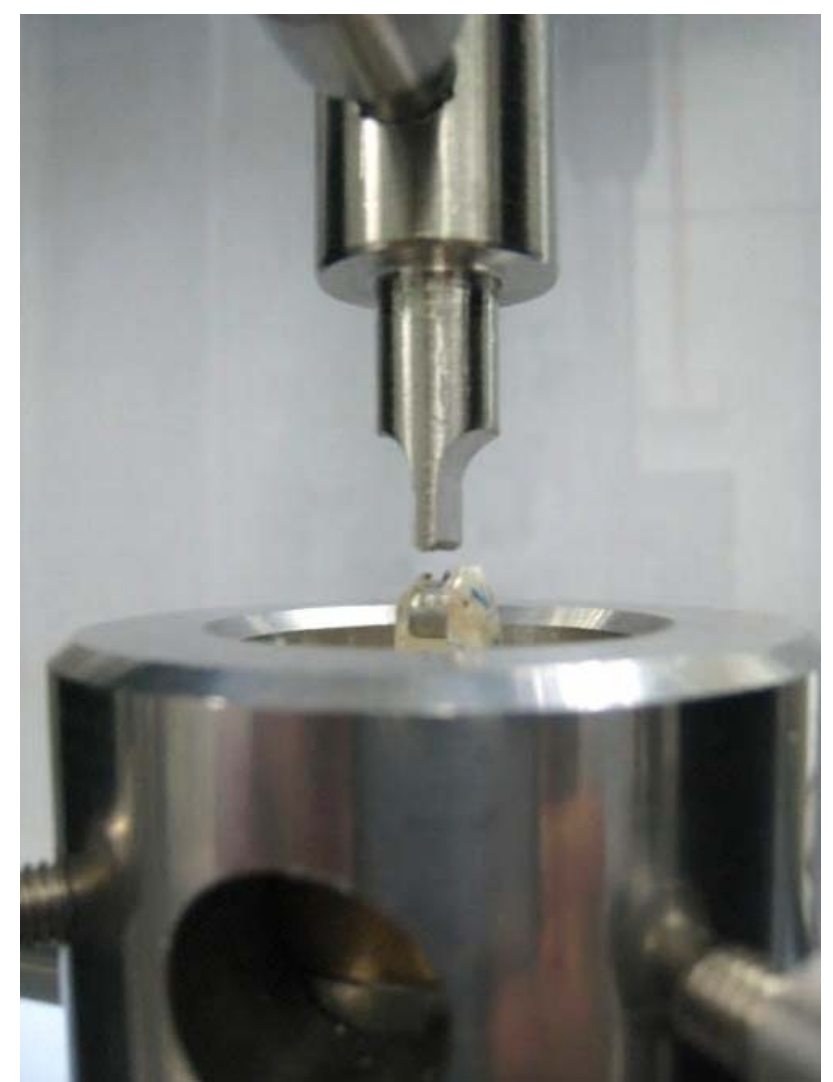

Figure 2. Tooth sample assembled to the universal testing machine ready to be loaded along its long axis.

tal and tooth length dimensions were standardized as much as possible to avoid dimensional variations that might affect the results.

The lateral condensation technique was used in the current study. It is the most commonly used technique in the studies evaluating the fracture resistance of postrestored teeth $[29,30]$. Therefore, its use facilitates comparison with other studies.

Deterioration of the marginal adaptation of a restored tooth has been reported after thermocycling [31]. Therefore, thermocycling was used in this study to simulate the conditions in the oral cavity. Thermocycling procedure was carried out according to ISO (ISO/TS 11405/ 2003).

In this in vitro study, attempts were made to simulate the periodontal ligament of natural teeth. Therefore, roots were not embedded directly into the acrylic resin blocks. The roots were painted with a thin layer of polyvinyl siloxane material (Exaflex, GC America Inc., USA). The elastic property of the material provides a non-concentrated stress area in the cervical region of the teeth and allows better distribution of stress from crown to root $[30,32]$.

There are a few factors which can influence the results of the fracture resistance studies. These include the tooth 
Table 2. Mean force of fracture (N) and standard deviation (SD).

\begin{tabular}{|c|c|c|c|c|c|}
\hline \multirow{2}{*}{ Groups } & \multirow{2}{*}{$\mathbf{N}$} & \multirow{2}{*}{ Mean (N) } & \multirow{2}{*}{ SD } & \multicolumn{2}{|c|}{ 95\% Confidence Interval } \\
\hline & & & & Lower Bound & Upper Bound \\
\hline $1(\mathrm{ST})$ & 10 & 860.11 & 309.87 & 686.49 & 1033.73 \\
\hline 2 (MOD-C) & 10 & 801.79 & 393.52 & 628.17 & 975.41 \\
\hline 3 (MOD-P-C) & 10 & 761.39 & 153.37 & 587.77 & 935.01 \\
\hline 4 (MOD-A) & 10 & 737.14 & 230.69 & 563.53 & 910.76 \\
\hline 5 (MOD-P-A) & 10 & 707.85 & 209.56 & 534.24 & 881.47 \\
\hline
\end{tabular}

mounting method, type of load application device, and crosshead speed [33]. During fracture strength testing, the point of contact between the loading bar and the occlusal surface of the teeth may differ from sample to other. This might then be the cause of a large standard deviation of the results of fracture strength testing studies. It was concluded that the best method to measure the fracture resistance of premolars was to use a cylinder of a defined diameter [34]. Therefore, a cylindrical bar of 2 $\mathrm{mm}$ diameter was used in this study to load the samples and was quite suitable to achieve a contact with the restoration and cusps inclines [31].

In view of the result reported in this study, sound teeth group (ST) showed the highest fracture resistance. This was followed by nanocomposite restored group (MODC). It has been shown that the restorative as well as endodontic procedures reduce the stiffness of teeth [35]. It is also reported that the restorative procedures were the greatest contributors to the loss of tooth stiffness. Surprisingly, endodontic procedures reduced tooth stiffness by only $5 \%$ through the access opening, while MOD cavity preparation reduced tooth stiffness by more than $60 \%[35]$.

According to the two-way ANOVA test, there was no statistically significant difference $(P>0.05)$ between the group restored with nanocomposite (MOD-C) and the group restored with amalgam (MOD-A), although descriptively, there was a difference in the values of the fracture load between each group. On the other hand, the two groups with glass fiber posts (MOD-P-C and MOD-P-A) did not show any statistically significant difference $(P>0.05)$ with the two groups without glass fiber posts (MOD-C and MOD-A). Therefore, the hypothesis that there would be no difference in fracture strength between endo-treated teeth restored with amalgam core and composite core restorations was supported by the results of this study. The second hypothesis that the use of glass fiber post in endo-treated teeth would not influence the fracture strength was also found to be accepted.

There are a few reasons which may have accounted for the difference in the result of our study from other studies. This may include the small sample size, the type of teeth used, the direction and speed of loading force, measurement and extent of MOD cavity, different etching and bonding systems used in different studies, type of amalgam and composite resins used, and finally the type of glass fiber post (brand, size, length as well as diameter) used. The primary cause for this difference is the small sample size, whereby only 10 samples were used in each group. However, other studies have used the same sample size of 10 in each group [36,37].

It has been reported that the loss of dental structure and the presence of fiber post restoration reduced the fracture resistance and tend to create a higher stress concentrations in the tooth-restoration complex [38]. However, another study has reported that the fracture resistance of endo-treated mandibular molars restored using resin composite was not affected by the presence or absence of glass fiber post [5].

An in vitro study has found that prior to the restoration with a composite resin, acid-etching procedure done on MOD cavity significantly increase fracture resistance [39]. It has been shown that amalgam-restored teeth were less resistant to fracture compared to packable composite and ormocer-restored teeth [36]. Amalgam restoration actually does not strengthen the teeth and behaves as a bulk replacement of lost tooth structure. Similarly, the teeth restored with conventional amalgam were significantly weaker than those teeth restored with bonded amalgam and composite resin [9]. The use of direct composite resin restorations provided significantly greater fracture resistance compared to teeth restored with amalgam [40]. This is because of the bonding behavior of composite resin restoration and tooth structure to form a single body.

From the results of our study, glass fiber post with nanocomposite restoration showed higher fracture loads than glass fiber post with amalgam restoration, although both group had descriptively lower fracture loads than restoration without fiber posts. It has been reported that tooth bonded posts can significantly increase the tooth strength [41]. Nano-type resin composite can bond to the glass fiber post and remaining tooth structure which increase retention. The stress can be distributed equally in the tooth and resin composite because of the intimate 
mechano-chemical bonding with the adhesive [3]. On the other hand, amalgam has no adhesive properties to the post and tooth structure. Upon the exertion of the intra-oral forces, the wedging effect between the buccal and lingual cusp tend to force the cusp apart [42].

As a limitation in this study, a control group consisting only of intact teeth was used, however, there was no negative control group which should be consisted of prepared teeth but without filling. Therefore, this issue should be considered in future studies. The conditions of the this study is not completely similar to the real intra-oral conditions, although an attempt was made to simulate the oral environment, thus, the results are difficult to apply directly as that in the clinical practice. The applied load was only in one direction and one point, which did not simulate many ways of masticatory force exertion, as well as parafunctional forces. Therefore, further studies on the longevity of the restorative techniques simulating the clinical conditions and the possible influence of parafunctional forces must be conducted.

\section{CONCLUSION}

Within the limitations of this study, it was observed that the type of restorative material and the usage of glass fiber post did not have any visible influence on the fracture resistance of the endo-treated mandibular premolars.

\section{REFERENCES}

[1] Ross, I.F. (1980) Fracture susceptibility of endodontically treated teeth. Journal of Endodontics, 6, 560-565. http://dx.doi.org/10.1016/S0099-2399(80)80151-8

[2] Assif, D. and Gorfil, C. (1994) Biomechanical considerations in restoring endodontically treated teeth. The Journal of Prosthetic Dentistry, 71, 565-567. http://dx.doi.org/10.1016/0022-3913(94)90438-3

[3] Schatz, D., Alfter, G. and Göz, G. (2001) Fracture resistance of human incisors and premolars: Morphological and patho-anatomical factors. Dental Traumatology, 17, 167-173.

http://dx.doi.org/10.1034/j.1600-9657.2001.170406.x

[4] Soares, C.J., Martins, L.R., Fonseca, R.B., Correr-Sobrinho, L. and Fernandes Neto, A.J. (2006) Influence of cavity preparation design on fracture resistance of posterior Leucite-reinforced ceramic restorations. The Journal of Prosthetic Dentistry, 95, 421-429. http://dx.doi.org/10.1016/j.prosdent.2006.03.022

[5] Salameh, Z., Sorrentino, R., Papacchini, F., Ounsi, H.F., Tashkandi, E., Goracci, C., et al. (2006) Fracture resistance and failure patterns of endodontically treated molars restored using resin composite with or without translucent glass fiber posts. Journal of Endodontics, 32, 752755. http://dx.doi.org/10.1016/j.joen.2006.02.002

[6] Wagnild, G.W. and Mueller, K.I. (2002) Restoration of the endodontically treated tooth. In: Cohen, S., Burns, R.C., Pathways of the Pulp, 8th Eition, Mosby Elesevier,
St Loius, 765-795.

[7] Messer, H.H. and Wilson, P.R. (2002) Preparation for restoration and temporization. In: Walton, R.E. and Torabinejad, M., Eds., Principles and Practice of Endodontics, 3rd Edition, W.B. Saunders Company, Philadelphia, 268-281.

[8] Schwartz, R.S. and Fransman, R. (2005) Adhesive dentistry and endodontics: Materials, clinical strategies and procedures for restoration of access cavities: A review. Journal of Endodontics, 31, 151-165. http://dx.doi.org/10.1097/01.don.0000155222.49442.a1

[9] Sagsen, B. and Aslan, B. (2006) Effect of bonded restorations on the fracture resistance of root filled teeth. International Endodontic Journal, 39, 900-904.

[10] Mondelli, R.F., Barbosa, W.F., Mondelli, J., Franco, E.B. and Carvalho, R.M. (1998) Fracture strength of weakened human premolars restored with amalgam with and without cusp coverage. American Journal of Dentistry, 11, 181-184.

[11] Kelly, P.G. and Smales, R.J. (2004) Long-term cost-effectiveness of single indirect restorations in selected dental practices. British Dental Journal, 196, 639-643. http://dx.doi.org/10.1038/sj.bdj.4811283

[12] Roulet, J.F. (1997) Benefits and disadvantages of toothcoloured alternatives to amalgam. Journal of Dentistry, 25, 459-473. http://dx.doi.org/10.1016/S0300-5712(96)00066-8

[13] Tobi, H., Kreulen, C.M., Vondeling, H. and van Amerongen, W.E. (1999) Cost-effectiveness of composite resins and amalgam in the replacement of amalgam Clas II restorations. Community Dentistry and Oral Epidemiology, 27, 137-143. http://dx.doi.org/10.1111/j.1600-0528.1999.tb02003.x

[14] Assif, D., Nissan, J., Gafni, Y. and Gordon, M. (2003) Assessment of the resistance to fracture of endodontically treated molars restored with amalgam. The Journal of Prosthetic Dentistry, 89, 462-465. http://dx.doi.org/10.1016/S0022-3913(02)52748-7

[15] Hernandez, R., Bader, S., Boston, D. and Trope, M. (1994) Resistance to fracture of endodontically treated premolars restored with new generation dentine bonding systems. International Endodontic Journal, 27, 281-284. http://dx.doi.org/10.1111/j.1365-2591.1994.tb00269.x

[16] Ausiello, P., De Gee, A.J., Rengo, S. and Davidson, C.L. (1997) Fracture resistance of endodonticallytreated premolars adhesively restored. American Journal of Dentistry, 10, 237-241.

[17] Soares, P.V., Santos-Filho, P.C., Gomide, H.A., Araujo, C.A., Martins, L.R. and Soares, C.J. (2008) Influence of restorative technique on the biomechanical behavior of endodontically treated maxillary premolars. Part II: strain measurement and stress distribution. The Journal of Prosthetic Dentistry, 99, 114-122. http://dx.doi.org/10.1016/S0022-3913(08)60027-X

[18] Shillingburg, H.T., Hobo, S., Whitsett, L.D., Jacobi, R. and Brackett, S.E. (1997) Fundamentals of fixed prosthodontics, 3rd Edition, Quintessence, Chicago, 185.

[19] Suliman, A.A., Boyer, D.B. and Lakes, R.S. (1993) Cusp 
movement in premolars resulting from composite polymerization shrinkage. Dental Materials, 9, 6-10. http://dx.doi.org/10.1016/0109-5641(93)90096-9

[20] Carvalho, R.M., Pereira, J.C., Yoshiyama, M. and Pashley, D.H. (1996) A review of polymerization contraction: The influence of stress development versus stress relief. Operative Dentistry, 21, 17-24.

[21] Levin, L., Coval, M. and Geiger, S.B. (2007) Cross-sectional radiographic survey of amalgam and resin-based composite posterior restorations. Quintessence International, 38, 511-514.

[22] Schwartz, R.S. and Robbins, J.W. (2004) Post placement and restoration of endodontically treated teeth: A literature review. Journal of Endodontics, 30, 289-301. http://dx.doi.org/10.1097/00004770-200405000-00001

[23] Fokkinga, W.A., Le Bell, A.M., Kreulen, C.M., Lassila, L.V., Villittu, P.K. and Creugers, N.H. (2005) Ex vivo fracture resistance of direct composite complete crowns with and without posts on maxillary premolars. International Endodontic Journal, 38, 230-237. http://dx.doi.org/10.1111/j.1365-2591.2005.00941.x

[24] Baraban, D.J. (1972) Immediate restoration of pulpless teeth. The Journal of Prosthetic Dentistry, 28, 607-612. http://dx.doi.org/10.1016/0022-3913(72)90109-6

[25] Sidoli, G.E., King, P.A. and Setchell, D.J. (1997) An in vitro evaluation of carbon fiber based post and core system. The Journal of Prosthetic Dentistry, 78, 5-9. http://dx.doi.org/10.1016/S0022-3913(97)70080-5

[26] Ferrari, M., Cagidiaco, M.C., Grandini, S., De Sanctis, M. and Goracci, C. (2007) Post placement affects survival of endodontically treated premolars. Journal of Dental Research, 86, 729-734.

http://dx.doi.org/10.1177/154405910708600808

[27] Hernandez, R., Bader, S., Boston, D. and Trope, M. (1994) Resistance to fracture of endodontically treated premolars restored with new generation dentine bonding systems. International Endodontic Journal, 27, 281-284. http://dx.doi.org/10.1111/j.1365-2591.1994.tb00269.x

[28] Kim, Y.H. and Lee, J.H. (2012) Influence of modification in core building procedure on fracture strength and failure patterns of premolars restored with fiber post and composite core. The Journal of Advanced Prosthodontics, 4, 37-42. http://dx.doi.org/10.4047/jap.2012.4.1.37

[29] Cormier, C.J., Burns, D.R. and Moon, P. (2001) In vitro comparison of the fracture resistance and failure mode of fiber, ceramic, and conventional post systems at various stages of restoration. Journal of Prosthodontics, 10, 26-36. http://dx.doi.org/10.1111/j.1532-849X.2001.00026.x

[30] Akkayan, B. and Gülmez, T. (2002) Resistance to fracture of endodontically treated teeth restored with different post systems. The Journal of Prosthetic Dentistry, 87, 431-437. http://dx.doi.org/10.1067/mpr.2002.123227

[31] Reill, M.I., Rsentritt, M., Naumann, M. and Handel, G. (2008) Influence of core material on fracture resistance and marginal adaptation of restored root filled teeth. International Endodontic Journal, 41, 424-430.
[32] Newman, M.P., Yaman, P., Dennison, J., Rafter, M. and Billy, E. (2003) Fracture resistance of endodontically treated teeth restored with composite posts. The Journal of Prosthetic Dentistry, 89, 360-367. http://dx.doi.org/10.1067/mpr.2003.75

[33] Burke, F.J., Wilson, N.H. and Watts, D.C. (1993) The effect of cavity wall taper on fracture resistance of teeth restored with resin composite inlays. Operative Dentistry, 18, 230-236.

[34] Burke, F.J. and Watts, D.C. (1994) Fracture resistance of teeth restored with dentin-bonded crowns. Quintessence International, 25, 335-340.

[35] Reeh, E.S., Messer, H.H. and Douglas, W.H. (1989) Reduction in tooth stiffness as a result of endodontic and restorative procedures. Journal of Endodontics, 15, 512-516. http://dx.doi.org/10.1016/S0099-2399(89)80191-8

[36] Hürmüzlü, F., Kİremİtci், A., Serper, A., Altundaşar, E. and Sİso, S.H. (2003) Fracture resistance of endodontically treated premolars restored with ormocer and packable composite. Journal of Endodontics, 29, 838-840. http://dx.doi.org/10.1097/00004770-200312000-00014

[37] Soares, P.V., Santos-Filho, P.C.F., Martins, L.R.M. and Soares, C.J. (2008) Influence of restorative technique on the biomechanical behaviour of endodontically treated maxillary premolars. Part I: Fracture resistance and fracture mode. The Journal of Prosthetic Dentistry, 99, 30-37. http://dx.doi.org/10.1016/S0022-3913(08)60006-2

[38] Soares, C.J., Soares, P.V., de Freitas Santos-Filho, P.C., Castro, C.G., Magalhaes, D. and Versluis, A. (2008) The influence of cavity design and glass fiber posts on biomechanical behavior of endodontically treated premolars. Journal of Endodontics, 34, 1015-1019. http://dx.doi.org/10.1016/j.joen.2008.05.017

[39] Trope, M., Langer, I., Maltz, D. and Tronstad, L. (1986) Resistance to fracture of restored endodontically treated premolars. Dental Traumatology, 2, 35-38. http://dx.doi.org/10.1111/j.1600-9657.1986.tb00120.x

[40] Soares, P.V., Santos-Filho, P.C.F., Martins, L.R.M. and Soares, C.J. (2008) Influence of restorative technique on the biomechanical behavior of endodontically treated maxillary premolars. Part II: Strain measurement and stress distribution. The Journal of Prosthetic Dentistry, 99, 114-122. http://dx.doi.org/10.1016/S0022-3913(08)60027-X

[41] Mortazavi, V., Fathi, M., Katiraei, N., Shahnaseri, S., Badrian, H. and Khalighinejad, N. (2012) Fracture resistance of structurally compromised and normal endodontically treated teeth restored with different post systems: An in vitro study. Dental Research Journal, 9, 185-191. http://dx.doi.org/10.4103/1735-3327.95234

[42] Hood, J.A. (1991) Biomechanics of the intact, prepared and restored tooth: Some clinical implications. International Dental Journal, 41, 25-32. 